\title{
Tissue-Based Immunohistochemical Markers for Diagnosis and Classification of Renal Cell Carcinoma
}

\author{
Liang G. Qu, $₫ 1,2$ Vaisnavi Thirugnanasundralingam, ${ }^{3}$ Damien Bolton,, 2 \\ Antonio Finelli, ${ }^{4}$ Nathan Lawrentschuk $2,3,5,6$ \\ ${ }^{1}$ Department of Urology, Austin Health, Heidelberg, Australia, ${ }^{2}$ Department of Surgery, University of Melbourne, Australia, ${ }^{3}$ Department of Urology, Royal Melbourne \\ Hospital, Melbourne, Australia, ${ }^{4}$ Division of Surgical Oncology, Princess Margaret Hospital, University Health Network, University of Toronto, Canada, ${ }^{5}$ Department of \\ Surgical Oncology, Peter MacCallum Cancer Centre, Melbourne, Australia, ${ }^{6}$ EJ Whitten Prostate Cancer Research Centre, Epworth Healthcare, Melbourne, Australia
}

\begin{abstract}
The development and description of renal cell carcinoma (RCC) subtypes has led to an increase in demand for tissue biomarkers. This has implications not only in informing diagnosis, but also in guiding treatment selection and in prognostication. Although historically, many immunohistochemical (IHC) stains have been widely characterized for RCC subtypes, challenges may arise in interpreting these results. These may include variations in tumor classification, specimen collection and processing, and IHC techniques. In light of the reclassification of RCC subtypes in 2016, there remains a requirement for a comprehensive outline of tissue biomarkers that may be used to differentiate between RCC subtypes and distinguish these from other non-renal neoplasms. In this review, concise summaries of the commonest RCC subtypes, including clear cell, papillary, and chromophobe RCC, have been provided. Important differences have been highlighted between chromophobe RCC and renal oncocytomas. An overview of the current landscape of tissue biomarkers in other RCC subtypes has also been explored, revealing the variable staining results reported for some markers, whilst highlighting the essential markers for diagnosis in other subtypes.
\end{abstract}

\section{Introduction}

Classifying renal cell carcinoma (RCC) into its various subtypes relies on a range of diagnostic techniques. These involve the analysis of anatomical, morphological, immunohistochemical (IHC), and molecular characteristics. IHC tissue biomarkers have maintained a useful role in aiding the diagnosis and subtyping of RCC [1]. In addition, tissue biomarkers may aid in the differentiation of non-renal neoplasms or metastatic disease. Its other uses include prognostication, as well as guidance of treatment selection $[2,3]$.

Advances have been made in IHC staining for RCC classification; however, challenges arise in the subtyping of RCC. Substantial staining heterogeneity exists across and within tumor subtypes [4]. Variations in processing may lead to inconsistencies in reported immunoreactivity or staining patterns [4]. Ongoing revision of the classification of renal cell tumors (Table 1) by the World Health Organization and International Society of Urological Pathology creates difficulty in interpreting older literature $[5,6]$. There is increasing demand for smaller volume samples to be analyzed, as diagnostic biopsies are performed more frequently. Although some of the described markers may not yet be commonly encountered in daily clinical practice, IHC staining remains useful in indicating the presence or absence of such markers, and in relaying quantitative information such as staining extent.

\section{Key Words}

Tissue-based markers, immunohistochemistry, renal cell carcinoma, cancer subtyping.

\section{Competing Interests}

None declared.

\section{Article Information}

Received on June 23, 2020

Accepted on August 3, 2020

Soc Int Urol J. 2020;1(1):68-76 


\author{
Abbreviations \\ AMACR alpha-methylacyl coenzyme A racemase \\ BAP1 BRCA1-associated protein 1 \\ CAIX carbonic anhydrase 9 \\ ccRCC clear cell RCC \\ CD10 cluster differential marker 10 \\ chRCC chromophobe RCC \\ CK cytokeratin \\ EMA epithelial membrane antigen \\ hKIM-1 human kidney injury molecule-1 \\ HMWCK high molecular weight CK \\ IHC immunohistochemical \\ MiT microphthalmia-associated transcription \\ RCC renal cell carcinoma \\ RCCM RCC marker \\ RO renal oncocytoma
}

This review provides an update on the current landscape of tissue biomarkers for the diagnosis and classification of common RCC subtypes.

\section{Clear Cell RCC}

Clear cell RCC (ccRCC) is responsible for approximately $75 \%$ of diagnosed RCCs [5]. Its staining profile has been widely characterized; however, markers are still being described that may aid differentiation of ccRCC from other subtypes (Table 2). Carbonic anhydrase 9 (CAIX), a transmembrane protein responsible for $\mathrm{CO}_{2}$ transfer, stains along membranous non-necrotic areas $[7,8]$. A transmembrane mucin protein, epithelial membrane antigen (EMA), may also be present in up to $85 \%$ of specimens $[9,10]$. Human kidney injury molecule-1 (hKIM-1) is a type 1 transmembrane glycoprotein found in injured proximal tubules [11]. This marker can be expressed in ccRCCs but may also be found in other clear cell carcinomas of the ovaries or endometrium.

Cytokeratin (CK) staining in ccRCC may vary depending on the antibody used and the specific CK studied. Immunoreactivity in $60 \%$ of ccRCC specimens may be achieved for CK8 using CAM 5.2 antibody [12]. ccRCC does not typically stain for CK7 [8]. CK19 antibody may result in infrequent immunoreactivity in $20 \%$ of specimens [13]. Broad spectrum CK (pancytokeratin) may be detected using AE1/AE3 antibodies [14]. ccRCCs are not immunoreactive to $34 \beta E 12$, an antibody for high molecular weight CK (HMWCK) [13]. Vimentin, an intermediate filament protein found in mesenchymal cells, may be detected in $87 \%$ of specimens $[15,16]$. Lectins, carbohydrate-binding proteins, may also be used as markers in RCC.

\section{TABLE 1.}

The WHO/ISUP classification of renal cell tumors, 2016

The classification of renal cell tumors as described by World Health Organization and International Society for Urological Pathology, in 2016.

\section{Renal Cell Tumors}

Clear cell RCC

Multilocular cystic renal neoplasm of low malignant potential

Papillary RCC

Hereditary leiomyomatosis and renal cell carcinoma-associated RCC

Chromophobe RCC

Collecting duct carcinoma

Renal medullary carcinoma

Microphthalmia-associated transcription family translocation RCC

Succinate dehydrogenase-deficient RCC

Mucinous tubular and spindle cell carcinoma

Tubulocystic RCC

Acquired cystic disease-associated RCC

Clear cell papillary RCC

RCC, unclassified

Papillary adenoma

Renal oncocytoma

Previously, galectin-1 (51\%) and galectin-3 (78\%) have been detected in ccRCC [17].

It is important to note that a number of markers produce negative immunoreactivity in ccRCC. Alphamethylacyl coenzyme A racemase (AMACR), an enzyme found in peroxisomes and mitochondria involved in fatty acid oxidation, does not typically stain in ccRCC tissue [8]. There is usually minimal immunoreactivity for parvalbumin, a calcium-binding albumin protein, and similar negative staining for claudin 7,8 , and CD117 [16,18-21]. E-cadherin is also typically not expressed, although may be detectable in tumors of higher grade $[10,22,23]$. Kidney-specific cadherin (Ksp-cadherin), detectable in the distal convoluted tubules, can be expressed in moderate intensity in some specimens (30\%) [20]. BRCA1-associated protein 1 (BAP1), a protein with deubiquitinase properties, expresses nuclear staining in up to $81 \%$ of ccRCCs; wherein a loss of expression may be associated with higher grade of disease [24].

Sensitive but non-specific markers may prove useful in confirming RCCs, especially in determining the origin of metastatic deposits. RCC marker (RCCM), an 
antibody directed at the brush border of the proximal tubule, is present in $85 \%$ of ccRCC specimens [25]. However, it may also be detected in $27 \%$ of non-renal carcinoma specimens, including Müllerian-derived tumors with clear cell morphology, rendering it a non-specific marker for RCC [26]. Similarly, cluster differential marker 10 (CD10), is expressed in $94 \%$ of ccRCC specimens but may be detectable in many nonrenal tumors [27].

ccRCC may appear similar to chromophobe RCC (chRCC) because of their shared clear and eosinophilic morphology. To minimize the number of markers used to differentiate tumor subtypes, a suggested panel of IHC markers should include vimentin, RCCM, CAIX, Ksp-cadherin, CD117, and parvalbumin.

\section{Papillary RCC}

Papillary RCC (pRCC) is the second most common RCC subtype, representing 15\% of diagnosed RCCs [5]. pRCCs demonstrate diffuse immunoreactivity to AE1/ AE3 antibody and CAM 5.2 antibody, no reactivity to $34 \beta \mathrm{E} 12$, and strong membranous staining for CK7 [28]. Roughly $90 \%$ of pRCCs will express some CK19 on staining [13]. Other markers that are immunoreactive include AMACR, vimentin, RCCM, EMA, hKIM-1 and CD10 [11,25,27,29-31].

E-cadherin expression has been inconsistently described, likely because of variations in tumor grade or type, and in technique and processing [22]. Specimens were more likely to express E-cadherin if they were higher grade or if they were type 2 pRCC [22]. pRCCs do not express Ksp-cadherin [20]. Importantly, pRCC

\section{TABLE 2.}

Summary of immunohistochemical markers for common renal cell tumor subtypes A summary of the commonly described immunohistochemical markers and their expression is listed for clear cell RCC, papillary RCC, chromophobe RCC, and renal oncocytoma.

\begin{tabular}{|c|c|c|c|c|}
\hline Immunohistochemical marker & ccRCC & pRCC & chRCC & Renal oncocytoma \\
\hline $\begin{array}{r}\text { Pan-cytokeratin } \\
\text { (AE1/AE3) }\end{array}$ & + & + & + & variable \\
\hline CK7 & - & $\begin{array}{l}\text { Type 1: + } \\
\text { Type 2: - }\end{array}$ & + & - \\
\hline $\begin{array}{l}\text { CK8/CK18 } \\
\text { (CAM 5.2) }\end{array}$ & + & + & + & + \\
\hline CK19 & - & + & - & - \\
\hline HMWCK (34ßE12) & - & - & - & - \\
\hline EMA & + & + & + & + \\
\hline E-cadherin & - & variable & + & + \\
\hline Ksp-cadherin & - & - & + & + \\
\hline CAIX & + & - & - & - \\
\hline AMACR & - & + & - & - \\
\hline Vimentin & + & + & - & - \\
\hline Parvalbumin & - & variable & + & + \\
\hline c-Kit/CD117 & - & - & + & + \\
\hline CD10 & + & + & - & - \\
\hline RCCM & + & + & - & - \\
\hline hKIM-1 & + & + & - & - \\
\hline Caveolin-1 & + & + & + & - \\
\hline S100A1 & + & + & - & + \\
\hline
\end{tabular}

$+\geq 50 \%$ staining; $-<50 \%$ staining. 
usually do not stain for CAIX, though some specimens may be weakly immunoreactive near necrotic areas [8]. There is variable staining for parvalbumin but typically negative staining for CD117 [16,19,32]. Reported data for membranous staining of claudin 7 range from $28 \%$ to $78 \%$ of pRCCs $[33,34]$. Claudin 8 does not stain well in pRCCs in roughly $14 \%$ of specimens [34]. Up to $83 \%$ may express galectin-1, whilst less than 6\% of pRCC stain for galectin-3 [17]. BAP1 is reported to be expressed across all pRCC specimens [24].

To assist with classifying a RCC with papillary features, a marker panel should consist of CK7, AMACR, CD10, RCCM, TFE3, and CD57 [30,35].

\section{Chromophobe RCC}

Chromophobe RCC (chRCC) represents up to $11 \%$ of diagnosed RCCs [7]. chRCC specimens are typically immunoreactive to CAM 5.2 antibody, AE1/AE3 antibody, as well as CK7 [7]. chRCC do not usually express CK19 or HMWCK [13].

Typically, chRCCs stain positive for EMA, E-cadherin, and Ksp-cadherin $[10,20,22,36]$. chRCCs are immunoreactive for parvalbumin and CD117 in most specimens $[16,37]$. chRCCs may also demonstrate immunoreactivity for tight junction proteins, claudin 7 (91\%), and less frequently, claudin $8(27 \%)[21,34]$. These tumor subtypes highly express galectin-1 (100\%), as well as galectin-3 (63\%) [17]. BAP1 may be expressed in up to $77 \%$ of specimens [24]. Rh family C glycoprotein (RHCG) as a membranous stain, is homogeneously expressed across chRCC specimens [38]. It is also expressed in renal oncocytomas, although staining patterns may differ in comparison [38]. Long noncoding RNA LINC01187 has also been studied. chRCC specimens demonstrate widespread expression of LINC01187 using RNA in situ hybridization, although this may also be identified in renal oncocytomas [38].

chRCCs do not express vimentin, although specimens may stain positive in sarcomatoid areas [7,15,39]. CAIX, hKIM-1, CD10, RCCM and AMACR are also not typically expressed in chRCCs $[7,11,27,29]$.

\section{Renal Oncocytoma}

Renal oncocytomas (ROs) remain challenging to diagnose because they share morphological and IHC features with chRCC. The IHC profile of ROs consist of variable immunoreactivity to AE1/AE3 antibody (49\%) and CK19 (40\%), while no expression is demonstrated for HMWCK [13]. ROs may stain for CAM 5.2 antibody [40].
ROs can also be immunoreactive for parvalbumin, CD117, E-cadherin, and sometimes EMA (52\%) $[10,16,36,37]$. They may express Ksp-cadherin in up to $76 \%$ of specimens [20]. There can be membranous staining for claudin 7 in 55\% and mixed pattern expression of claudin 8 in $92 \%$ of specimens $[21,33,34]$. It is important to note that ROs stain negative for vimentin, AMACR, CAIX, CD10, and RCCM $[27,29,30,39,41]$. Limited staining has been reported for hKIM-111.

Several markers to distinguish between ROs and chRCCs have been investigated. ROs typically stain negative for Hale's colloidal iron stain; however, variability in processing and technique has affected the interpretability and reproducibility of this staining technique [10]. CK7 staining may demonstrate focal positivity in ROs, which is in contrast to the diffuse staining observed in chRCCs [39]. S100A1, a calciumbinding protein, demonstrates consistent and diffuse cytoplasmic staining in ROs compared with chRCC, in which the positive staining rate for S100A1 is considerably lower [42]. Caveolin-1, a scaffolding protein, which was originally described as demonstrating expression in chRCC and not in ROs, has since been reported with variable expression and staining pattern, likely due to inconsistencies among subtypes [39,43-45].

Additional markers are currently being explored. Amylase a1A, a salivary-type digestive enzyme, produces $100 \%$ staining in RO specimens, compared with only $13 \%$ of chRCCs [46]. Wnt-5a, involved in tumor development, similarly produces $100 \%$ staining in RO specimens while only $16 \%$ of chRCCs may stain positive [47]. FXYD2, a marker coding for a subunit of a distal tubule $\mathrm{Na} / \mathrm{K}$ ATPase, stains in $17 \%$ of ROs, compared with $96 \%$ in chRCCs [48]. Ankyrin-repeated protein with a proline-rich region, a muscle protein, was present in $86 \%$ of ROs, compared with $0 \%$ in chRCC specimens [49]. CD63, a glycoprotein investigated for differential staining patterns, produces apical/ polar staining in $94 \%$ of ROs, which is in contrast to the diffuse staining pattern observed in $96 \%$ of chRCCs [50]. Transforming growth factor $\beta 1$, a cytokine, demonstrates predominantly cytoplasmic staining in ROs, while producing membranous staining in chRCC specimens [51].

Other novel markers include FOXI1, a transcription factor identified in intercalated cells (positive in ROs) [52], ELA, a ligand of apelin receptor (positive in ROs) [52], caspase 3, a protease involved in apoptosis (positive in chRCCs) [53], nuclear expression of leptin (in ROs) [54], loss of RB1 (in chRCCs) [55], and nuclear staining of tyrosine kinase ERBB4 [55]. 


\section{Other RCC Subtypes}

In clear cell papillary RCC (ccpRCC), there is diffuse positive cytoplasmic immunoreactivity for CK7. In addition, there can be a diffuse membranous expression of CAIX as in ccRCC; however, a unique "cup-like" pattern may be identified on basolateral tumor cells [8]. AMACR is not usually expressed in ccpRCC. There can be variable expression for HMWCK using $34 \beta E 12$ antibody [7]. In contrast to ccRCCs, this subtype is negative for CD10 and positive for CK7. Unlike pRCC, this subtype is negative for AMACR and CD10.

Microphthalmia-associated transcription (MiT) family translocation carcinomas warrant careful discrimination from their morphologically similar counterparts, namely ccRCC and pRCC, because of the differences in disease outcome, prognosis, and management [56]. MiT family translocation carcinomas do not express CKs or EMA but do express CD10 and RCCM. Although the primary diagnostic modality is a fluorescence in situ hybridization assay, IHC markers may be used to distinguish MiT family translocation RCCs [57]. Translocation RCCs involving chromosome Xp11.2 are negative for CK7 and CAIX, but positive for AMACR [29]. A specific IHC marker, TFE3, may be used to identify this transcription factor that is overexpressed in this particular translocation [8]. A similar translocation-related marker, TFEB, may be used to distinguish cells affected by a translocation at chromosome 6p21 [58]. In relation to both chromosomal loci, an additional marker, cathepsin- $K$, may also be overexpressed and detectable in both Xp11.2 and 6p21 translocation tumors. Cathepsin- $\mathrm{K}$ is expressed in TFEB translocation RCCs, and in up to $60 \%$ of TFE3 RCCs $[59,60]$. IHC markers can be used as a supportive aid to diagnosis, but must be cautiously supplemented by other diagnostic tools, because of the occurrence of false positive and false negative results [61].

Acquired cystic disease-associated RCCs are slowgrowing tumors that occur within cysts. These tumors can occur multi-focally and bilaterally [14,62]. Their diagnosis can often be made according to their characteristic morphological features; however, IHC markers may assist with diagnosis. This particular subtype of RCC is often immunoreactive to AMACR, AE1/AE3 antibody, CAM 5.2 antibody, vimentin, CD10, and RCCM. They have been reported to demonstrate variable expression for CAIX and CK7 [62,63].

Tubulocystic RCCs, although similar to pRCCs morphologically, may be distinguished using IHC markers. These tumors stain positive for CK7, CD10, PAX2, PAX8, and diffusely for AMACR [29]. In a study of 3 tubulocystic RCC specimens, all 3 cases stained positive for CK19, as well as vimentin, while being negative for HMWCK [15].
IHC markers for succinate dehydrogenase-deficient RCCs have been characterized in limited reports. These tumors have variable $\mathrm{CK}$ expression but have positivity for PAX8, EMA, and Ksp-cadherin. Typically, these tumors stain negative for vimentin, CD117, RCCM, and CAIX $[64,65]$. These tumors require a loss of the SDHB gene, which codes a subunit for succinate dehydrogenase enzyme [64]. A negative stain for SDHB can be useful to confirm this diagnosis.

It is important to differentiate collecting duct carcinomas from urothelial carcinomas. These tumors stain positive for CK5/6, CK7, CK8, CK19, as well as for HMWCK [15] and are immunoreactive for vimentin, PAX2, and PAX8 $[10,15]$. They usually stain negative for CD10. In addition to PAX8, urothelial markers p63 and GATA3 may be used to rule out a urothelial tumor [30].

Renal medullary carcinoma is closely related to collecting duct carcinomas and may be identified in individuals with sickle cell trait or anemia $[66,67]$. This subtype demonstrates immunoreactivity for CK7 and AE1/AE3 antibody but not to $34 \beta E 12$ [15]. There is variable EMA expression. These tumors stain positive for PAX2 and PAX8. SMARCB1, a nuclear transcriptional regulator, can be used to distinguish renal medullary carcinoma from collecting duct carcinoma [68]. Another transcription factor, OCT3/4, can be used as a marker to distinguish this tumor from urothelial or collecting duct carcinomas [69].

Multilocular cystic renal cell neoplasms of low malignant potential demonstrate IHC features that are identical to those found in low-grade ccRCCs. This subtype is immunoreactive to CAM 5.2 antibody, EMA, CK7, CAIX, and PAX2 [70,71]. Variable expression has been reported for CD10 [70,71].

Histologically, hereditary leiomyomatosis renal cell carcinoma-associated RCC (HLRCC) was historically reported as being similar to type 2 pRCC or collecting duct carcinomas. In these tumors, there can be positive staining for CK7, CAM 5.2 antibody, and CD10. The stroma is negative for CD117. Loss of the fumarate hydratase gene is specific for HLRCC [72]. Because of increasing fumarate, IHC staining may result from accumulating S-(2-succinyl cysteine) (S2C), where strong nuclear and cytoplasmic expression has been described. S2C can, however, be found in type 2 pRCCs [72].

Mucinous tubular and spindle cell carcinoma (MTSCC) displays several IHC similarities to pRCC, despite being genetically dissimilar. These tumors are immunoreactive for AMACR, CK7, PAX2, E-cadherin and EMA, but stain negative for RCCM, 34ßE12, and CD117 $[15,73,74]$. There can be variable staining for vimentin [15]. MTSCC differs from pRCC, with a lower 
level of staining for CD10 (15\% versus 100\%) [73]. Reports have also described the in situ hybridization expression of VSTM2A. VSTM2A is expressed in moderate to high levels in MSTCC, with a reported diagnostic area under receiver operating characteristics curve of 99.2\% [75].

\section{Other Tissue Markers}

Other useful markers may help distinguish RCC from non-renal cell tumor origins. PAX2 and PAX8 are transcription factors implicated in kidney and Müllerian organ development [30,76]. PAX2 and PAX8 are usually expressed and found diffusely in normal kidney tissue; however, they are also present in up to $90 \%$ of renal neoplasms. PAX2 differs from PAX8 in that it is not usually expressed in ROs or chRCCs. In addition, urothelial carcinomas do not express PAX2 or PAX8, thereby demonstrating their utility in determining tumor origin [77].

GATA3, an endothelial cell transcription factor, is a marker for urothelial carcinoma that consistently stains negative in RCC specimens [78]. CA-125, a marker classically associated with ovarian cancer, may also be used as a negative marker for RCCs, distinguishing them from other tumors of clear cell morphology [26]. CK20 is a useful negative marker for ruling out renal cell neoplasms [30]. Most RCCs typically stain negative for CK20, with the exception of previously reported eosinophilic solid cystic RCCs [79]. These may be useful in ruling out other CK20+ tumors, such as urothelial, ovarian, or colorectal carcinomas. Other markers useful in work-up for ruling out non-renal neoplasms include RCCM, CD10, vimentin and CKs.

Additional tissue-based markers are being investigated, as guided by the recent advances in the study of RCC genomic alterations. Commonly reported

\section{References}

1. Williamson SR, Gill AJ, Argani P, et al. Report From the International Society of Urological Pathology (ISUP) Consultation Conference on Molecular Pathology of Urogenital Cancers: III: Molecular Pathology of Kidney Cancer. Am J Surg Pathol. 2020;44(7):e47-e65.

2. Srigley JR, Delahunt B, Eble JN, et al. The International Society of Urological Pathology (ISUP) Vancouver Classification of Renal Neoplasia. Am J Surg Pathol. 2013;37(10):1469-89.

3. Signoretti S, Flaifel A, Chen YB, Reuter VE. Renal Cell Carcinoma in the Era of Precision Medicine: From Molecular Pathology to TissueBased Biomarkers. J Clin Oncol. 2018:JC02018792259.

4. Di Napoli A, Signoretti S. Tissue biomarkers in renal cell carcinoma: issues and solutions. Cancer. 2009;115(10 Suppl):2290-7.

5. Moch H, Cubilla AL, Humphrey PA, Reuter VE, Ulbright TM. The 2016 WHO classification of tumours of the urinary system and male genital organs-Part A: renal, penile, and testicular tumours. Eur Urol. 2016;70(1):93-105. altered genes for ccRCC include $V H L, P B R M 1$, and SETD2 [80]. pRCC may demonstrate MET mutation, while chRCC may exhibit TP53 or PTEN mutations [81]. Some genomic alterations may also aid differentiation of chRCC and RO [81]. Although genomic alterations have largely been studied using next-generation sequencing techniques, some have been adapted to IHC. VHL, a tumor suppressor gene, is commonly inactivated in both hereditary and sporadic ccRCCs [82]. The IHC detection of its gene product is expressed in up to $90 \%$ of primary renal tumors and $86 \%$ of metastatic RCC specimens [83]. However, it may also be identified in non-renal tumors such as clear cell carcinomas of the ovary or uterus [83]. PBRM1 has also been studied as an IHC marker; however, its application is mainly to aid prognostication. A loss of PBRM1 expression is associated with late tumor stage and poor differentiation [84]. Similarly, IHC SETD2 expression has been identified in metastatic RCC, and demonstrates utility in determining likely prognostic outcomes [85]. Future studies should continue to investigate the adaptation of altered gene products to the field of diagnostic tissue markers.

\section{Conclusion}

The characterization of RCC subtypes using tissue biomarkers must undergo ongoing review as new markers and techniques are developed and described. IHC staining remains a useful method to subtype RCCs and to distinguish them from non-renal tumors, especially in small tissue volume specimens, such as in metastatic tissue biopsies. More study is required to further characterize the subtypes of RCC to further delineate them and improve the accuracy of diagnosis, treatment, and prognostication.

6. Taylor AS, Spratt DE, Dhanasekaran SM, Mehra R. Contemporary renal tumor categorization with biomarker and translational updates: a practical review. Arch Pathol Lab Med. 2019;143(12):1477-91.

7. Reuter VE, Tickoo SK. Differential diagnosis of renal tumours with clear cell histology. Pathology. 2010;42(4):374-83.

8. Alshenawy HA. Immunohistochemical panel for differentiating renal cell carcinoma with clear and papillary features. Pathol Oncol Res. 2015;21(4):893-9.

9. Lopez-Beltran A, Henriques V, Cimadamore A, et al. The Identification of immunological biomarkers in kidney cancers. Front Oncol. 2018;8:456.

10. Mazal PR, Exner M, Haitel A, et al. Expression of kidney-specific cadherin distinguishes chromophobe renal cell carcinoma from renal oncocytoma. Hum Pathol. 2005;36(1):22-8. 
11. Lin F, Zhang PL, Yang XJ, et al. Human kidney injury molecule-1 (hKIM-1): a useful immunohistochemical marker for diagnosing renal cell carcinoma and ovarian clear cell carcinoma. Am J Surg Pathol. 2007;31(3):371-81

12. Chu PG, Weiss LM. Cytokeratin 14 immunoreactivity distinguishes oncocytic tumour from its renal mimics: an immunohistochemical study of 63 cases. Histopathology. 2001;39(5):455-62.

13. Langner C, Wegscheider BJ, Ratschek M, Schips L, Zigeuner R. Keratin immunohistochemistry in renal cell carcinoma subtypes and renal oncocytomas: a systematic analysis of 233 tumors. Virchows Arch. 2004;444(2):127-34.

14. Warren AY, Harrison D. WHO/ISUP classification, grading and pathological staging of renal cell carcinoma: standards and controversies. World J Urol. 2018;36(12):1913-26.

15. Skinnider BF, Folpe $A L$, Hennigar $R A$, et al. Distribution of cytokeratins and vimentin in adult renal neoplasms and normal renal tissue: potential utility of a cytokeratin antibody panel in the differential diagnosis of renal tumors. Am J Surg Pathol. 2005;29(6):747-54.

16. Young AN, de Oliveira Salles PG, Lim SD, et al. Beta defensin-1, parvalbumin, and vimentin: a panel of diagnostic immunohistochemical markers for renal tumors derived from gene expression profiling studies using cDNA microarrays. Am J Surg Pathol. 2003;27(2):199-205.

17. Aboulhagag NA, El-Deek HEM, Sherif MF. Expression of galectin-1 and galectin-3 in renal cell carcinoma; immunohistochemical study. Ann Diagn Pathol. 2018;36:31-7.

18. Petit A, Castillo M, Santos M, Mellado B, Alcover JB, Mallofre C. KIT expression in chromophobe renal cell carcinoma: comparative immunohistochemical analysis of KIT expression in different renal cell neoplasms. Am J Surg Pathol. 2004;28(5):676-8.

19. Martignoni G, Pea M, Chilosi M, et al. Parvalbumin is constantly expressed in chromophobe renal carcinoma. Mod Pathol. 2001;14(8):760-7.

20. Adley BP, Gupta A, Lin F, Luan C, Teh BT, Yang XJ. Expression of kidney-specific cadherin in chromophobe renal cell carcinoma and renal oncocytoma. Am J Clin Pathol. 2006;126(1):79-85.

21. Osunkoya A0, Cohen C, Lawson D, Picken MM, Amin MB, Young AN. Claudin-7 and claudin-8: immunohistochemical markers for the differential diagnosis of chromophobe renal cell carcinoma and renal oncocytoma. Hum Pathol. 2009;40(2):206-10.

22. Langner C, Ratschek M, Rehak P, Schips L, Zigeuner R. Expression of MUC1 (EMA) and E-cadherin in renal cell carcinoma: a systematic immunohistochemical analysis of 188 cases. Mod Pathol. 2004;17(2):180-8.

23. Allory $Y$, Bazille $C$, Vieillefond A, et al. Profiling and classification tree applied to renal epithelial tumours. Histopathology. 2008;52(2):158-66.

24. Wi YC, Moon A, Jung MJ, et al. Loss of nuclear BAP1 expression is associated with high WHO/ISUP grade in clear cell renal cell carcinoma. J Pathol Trans/ Med. 2018;52(6):378.
25. McGregor DK, Khurana KK, Cao C, et al. Diagnosing primary and metastatic renal cell carcinoma: the use of the monoclonal antibody 'Renal Cell Carcinoma Marker'. Am J Surg Pathol. 2001;25(12):1485-92.

26. Mentrikoski MJ, Wendroth SM, Wick MR. Immunohistochemical distinction of renal cell carcinoma from other carcinomas with clear-cell histomorphology: utility of CD10 and CA-125 in addition to PAX-2, PAX-8, RCCma, and adipophilin. Appl Immunohistochem Mol Morphol. 2014;22(9):635-41.

27. Avery AK, Beckstead J, Renshaw AA, Corless CL. Use of antibodies to RCC and CD10 in the differential diagnosis of renal neoplasms. Am J Surg Pathol. 2000;24(2):203-10.

28. Renshaw AA, Zhang $H$, Corless CL, Fletcher JA, Pins MR. Solid variants of papillary (chromophil) renal cell carcinoma: clinicopathologic and genetic features. Am J Surg Pathol. 1997:21(10):1203-9.

29. Molinie V, Balaton A, Rotman S, et al. Alpha-methyl CoA racemase expression in renal cell carcinomas. Hum Pathol. 2006;37(6):698-703.

30. Shen SS, Truong LD, Scarpelli M, Lopez-Beltran A. Role of immunohistochemistry in diagnosing renal neoplasms: when is it really useful? Arch Pathol Lab Med. 2012;136(4):410-7.

31. Alexa A, Baderca F, Lighezan R, Zahoi DE, Izvernariu D. The diagnostic value of EMA expression in the renal parenchyma tumors. Rom J Morphol Embryol. 2011;52(3 Suppl):1019-25.

32. Ahmed EA, Youssif ME. Immunohistochemical study of c-KIT (CD117) expression in renal cell carcinoma. J Egypt Natl Canc Inst. 2009;21(2):121-32.

33. Hornsby CD, Cohen C, Amin MB, et al. Claudin-7 immunohistochemistry in renal tumors: a candidate marker for chromophobe renal cell carcinoma identified by gene expression profiling. Arch Pathol Lab Med. 2007;131(10):1541-6.

34. Lechpammer M, Resnick MB, Sabo E, et al. The diagnostic and prognostic utility of claudin expression in renal cell neoplasms. Mod Pathol. 2008;21(11):1320-9.

35. Tickoo SK, Reuter VE. Differential diagnosis of renal tumors with papillary architecture. Adv Anat Pathol. 2011;18(2):120-32.

36. Shen SS, Krishna B, Chirala R, Amato RJ, Truong LD. Kidney-specific cadherin, a specific marker for the distal portion of the nephron and related renal neoplasms. Mod Pathol. 2005;18(7):933-40.

37. Huo L, Sugimura J, Tretiakova MS, et al. C-kit expression in renal oncocytomas and chromophobe renal cell carcinomas. Hum Pathol. 2005;36(3):262-8

38. Skala SL, Wang X, Zhang Y, et al. Next-generation RNA sequencingbased biomarker characterization of chromophobe renal cell carcinoma and related oncocytic neoplasms. Eur Urol. 2020

39. El-Shorbagy SH, Alshenawy HA. Diagnostic utility of vimentin, CD117, cytokeratin-7 and caveolin-1 in differentiation between clear cell renal cell carcinoma, chromophobe renal cell carcinoma and oncocytoma. J Microsc Ultrastruct. 2017;5(2):90-6.

40. Stopyra GA, Warhol MJ, Multhaupt HA. Cytokeratin 20 immunoreactivity in renal oncocytomas. J Histochem Cytochem. 2001:49(7):919-20. 
41. Genega EM, Ghebremichael M, Najarian R, et al. Carbonic anhydrase IX expression in renal neoplasms: correlation with tumor type and grade. Am J Clin Pathol. 2010;134(6):873-9.

42. Kuroda N, Kanomata N, Yamaguchi T, et al. Immunohistochemical application of S100A1 in renal oncocytoma, oncocytic papillary renal cell carcinoma, and two variants of chromophobe renal cell carcinoma. Med Mol Morphol. 2011;44(2):111-5.

43. Garcia E, Li M. Caveolin-1 immunohistochemical analysis in differentiating chromophobe renal cell carcinoma from renal oncocytoma. Am J Clin Pathol. 2006;125(3):392-8.

44. Tamaskar I, Choueiri TK, Sercia L, Rini B, Bukowski R, Zhou M. Differential expression of caveolin-1 in renal neoplasms. Cancer. 2007;110(4):776-82.

45. Ng KL, Ellis RJ, Samaratunga H, Morais C, Gobe GC, Wood ST. Utility of cytokeratin 7, S100A1 and caveolin-1 as immunohistochemical biomarkers to differentiate chromophobe renal cell carcinoma from renal oncocytoma. Trans/ Androl Urol. 2019;8(Suppl 2):S123-S37.

46. Jain S, Roy S, Amin M, et al. Amylase alpha-1A (AMY1A): a novel immunohistochemical marker to differentiate chromophobe renal cell carcinoma from benign oncocytoma. Am J Surg Pathol. 2013;37(12):1824-30.

47. Rao Q, Liu XH, Zhou HB, Ma HH, Lu ZF, Zhou XJ. Expression analysis of Wnt-5a in renal epithelial neoplasms: distinguishing renal oncocytoma from a wide spectrum of renal cell carcinomas. Tumori. 2010;96(2):304-9.

48. Gaut JP, Crimmins DL, Lockwood CM, McQuillan JJ, Ladenson JH. Expression of the $\mathrm{Na}+/ \mathrm{K}_{+}-$transporting ATPase gamma subunit FXYD2 in renal tumors. Mod Pathol. 2013;26(5):716-24.

49. Shomori K, Nagashima Y, Kuroda N, et al. ARPP protein is selectively expressed in renal oncocytoma, but rarely in renal cell carcinomas. Mod Pathol. 2007;20(2):199-207.

50. Mete 0, Kilicaslan I, Gulluoglu MG, Uysal V. Can renal oncocytoma be differentiated from its renal mimics? The utility of antimitochondrial, caveolin 1, CD63 and cytokeratin 14 antibodies in the differential diagnosis. Virchows Arch. 2005;447(6):938-46.

51. Demirovic A, Cesarec S, Marusic Z, et al. TGF-beta1 expression in chromophobe renal cell carcinoma and renal oncocytoma. Eur J Histochem. 2014;58(1):2265.

52. Artas G, Kuloglu T, Dagli AF, et al. A promising biomarker to distinguish benign and malignant renal tumors: ELABELA. Niger $J$ Clin Pract. 2019;22(3):386-92.

53. Kowalewski A, Szylberg L, Tyloch J, et al. Caspase 3 as a novel marker to distinguish chromophobe renal cell carcinoma from oncocytoma. Pathol Oncol Res. 2019;25(4):1519-24.

54. Ng KL, Del Vecchio SJ, Samaratunga H, et al. Leptin and its receptor: can they help to differentiate chromophobe renal cell carcinoma from renal oncocytoma? Pathology. 2018;50(5):504-10.

55. Sun T, Hutchinson L, Zhou AG, et al. The utility of ERBB4 and RB1 immunohistochemistry in distinguishing chromophobe renal cell carcinoma from renal oncocytoma. Int J Surg Pathol. 2020;28(3):259-64.
56. Damayanti NP, Budka JA, Khella HWZ, et al. Therapeutic targeting of TFE3/IRS-1/PI3K/mTOR axis in translocation renal cell carcinoma. Clin Cancer Res. 2018;24(23):5977-89.

57. Green WM, Yonescu R, Morsberger L, et al. Utilization of a TFE3 break-apart FISH assay in a renal tumor consultation service. Am J Surg Pathol. 2013;37(8):1150-63.

58. Davis IJ, Hsi BL, Arroyo JD, et al. Cloning of an Alpha-TFEB fusion in renal tumors harboring the $t(6 ; 11)(p 21 ; q 13)$ chromosome translocation. Proc Natl Acad Sci U S A. 2003;100(10):6051-6.

59. Martignoni G, Bonetti F, Chilosi $\mathrm{M}$, et al. Cathepsin $\mathrm{K}$ expression in the spectrum of perivascular epithelioid cell (PEC) lesions of the kidney. Mod Pathol. 2012;25(1):100-11.

60. Martignoni G, Pea M, Gobbo S, et al. Cathepsin-K immunoreactivity distinguishes MiTF/TFE family renal translocation carcinomas from other renal carcinomas. Mod Pathol. 2009;22(8):1016-22.

61. Calio A, Segala D, Munari E, Brunelli M, Martignoni G. MiT family translocation renal cell carcinoma: from the early descriptions to the current knowledge. Cancers (Basel). 2019;11(8)

62. Przybycin CG, Harper HL, Reynolds JP, et al. Acquired cystic diseaseassociated renal cell carcinoma ( $A C D-R C C$ ): a multiinstitutional study of 40 cases with clinical follow-up. Am J Surg Pathol. 2018;42(9):1156-65.

63. Foshat M, Eyzaguirre E. Acquired cystic disease-associated renal cell carcinoma: review of pathogenesis, morphology, ancillary tests, and clinical features. Arch Pathol Lab Med. 2017;141(4):600-6.

64. Gill AJ, Hes 0, Papathomas T, et al. Succinate dehydrogenase (SDH)-deficient renal carcinoma: a morphologically distinct entity: a clinicopathologic series of 36 tumors from 27 patients. Am J Surg Pathol. 2014;38(12):1588-602.

65. Williamson SR, Eble JN, Amin MB, et al. Succinate dehydrogenasedeficient renal cell carcinoma: detailed characterization of 11 tumors defining a unique subtype of renal cell carcinoma. Mod Pathol. 2015;28(1):80-94.

66. Algaba F, Akaza H, Lopez-Beltran A, et al. Current pathology keys of renal cell carcinoma. Eur Urol. 2011;60(4):634-43.

67. Yang XJ, Sugimura J, Tretiakova MS, et al. Gene expression profiling of renal medullary carcinoma: potential clinical relevance. Cancer. 2004;100(5):976-85.

68. Ohe C, Smith SC, Sirohi D, et al. Reappraisal of morphologic differences between renal medullary carcinoma, collecting duct carcinoma, and fumarate hydratase-deficient renal cell carcinoma. Am J Surg Pathol. 2018;42(3):279-92.

69. Rao P, Tannir NM, Tamboli P. Expression of OCT3/4 in renal medullary carcinoma represents a potential diagnostic pitfall. Am J Surg Pathol. 2012;36(4):583-8.

70. Murshed KA, Akhtar M, Ben-Gashir M. Multilocular cystic renal neoplasm of low malignant potential extending into the perinephric adipose tissue. Hum Pathol. 2019;17:200305.

71. Williamson SR, Halat S, Eble JN, et al. Multilocular cystic renal cell carcinoma: similarities and differences in immunoprofile compared with clear cell renal cell carcinoma. Am J Surg Pathol. 2012;36(10):1425-33. 
72. Chen YB, Brannon AR, Toubaji A, et al. Hereditary leiomyomatosis and renal cell carcinoma syndrome-associated renal cancer: recognition of the syndrome by pathologic features and the utility of detecting aberrant succination by immunohistochemistry. Am J Surg Pathol. 2014;38(5):627-37.

73. Paner GP, Srigley JR, Radhakrishnan A, et al. Immunohistochemical analysis of mucinous tubular and spindle cell carcinoma and papillary renal cell carcinoma of the kidney: significant immunophenotypic overlap warrants diagnostic caution. Am J Surg Pathol. 2006;30(1):13-9.

74. Nathany S, Monappa V. Mucinous tubular and spindle cell carcinoma: a review of histopathology and clinical and prognostic implications. Arch Pathol Lab Med. 2020;144(1):115-8.

75. Wang $L$, Zhang $Y$, Chen $Y-B$, et al. VSTM2A overexpression is a sensitive and specific biomarker for mucinous tubular and spindle cell carcinoma (MTSCC) of the kidney. Am J Surg Pathol. 2018;42(12):1571-84.

76. Ozcan A, de la Roza G, Ro JY, Shen SS, Truong LD. PAX2 and PAX8 expression in primary and metastatic renal tumors: a comprehensive comparison. Arch Pathol Lab Med. 2012;136(12):1541-51.

77. Albadine R, Schultz L, Illei P, et al. PAX8 (+)/p63 (-) immunostaining pattern in renal collecting duct carcinoma (CDC): a useful immunoprofile in the differential diagnosis of CDC versus urothelial carcinoma of upper urinary tract. Am J Surg Pathol. 2010;34(7):965-9.
78. Mohammed KH, Siddiqui MT, Cohen C. GATA3 immunohistochemical expression in invasive urothelial carcinoma. Urol Oncol. 2016;34(10):432 e9- e13.

79. Trpkov K, Abou-Ouf H, Hes 0, et al. Eosinophilic solid and cystic renal cell carcinoma (ESC RCC): further morphologic and molecular characterization of ESC RCC as a distinct entity. Am J Surg Pathol. 2017;41(10):1299-308.

80. de Velasco G, Wankowicz SA, Madison R, et al. Targeted genomic landscape of metastases compared to primary tumours in clear cell metastatic renal cell carcinoma. Br J Cancer. 2018;118(9):1238-42.

81. Durinck S, Stawiski EW, Pavía-Jiménez A, et al. Spectrum of diverse genomic alterations define non-clear cell renal carcinoma subtypes. Nat Genet. 2015;47(1):13.

82. Kaelin WG. Molecular basis of the VHL hereditary cancer syndrome. Nat Rev Cancer. 2002;2(9):673-82.

83. Lin F, Shi J, Liu H, et al. Immunohistochemical detection of the von Hippel-Lindau gene product ( $\mathrm{pVHL}$ ) in human tissues and tumors: a useful marker for metastatic renal cell carcinoma and clear cell carcinoma of the ovary and uterus. Am J Clin Pathol. 2008;129(4):592-605.

84. Pawłowski R, Mühl SM, Sulser T, Krek W, Moch H, Schraml P. Loss of PBRM1 expression is associated with renal cell carcinoma progression. Int J Cancer. 2013;132(2):E11-E7.

85. Wang J, Liu L, Qu Y, et al. Prognostic value of SETD2 expression in patients with metastatic renal cell carcinoma treated with tyrosine kinase inhibitors. J Urol. 2016;196(5):1363-70. 